\title{
The pocket-creation method may facilitate endoscopic submucosal dissection of large colorectal sessile tumors $\square$
}

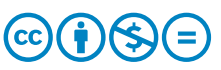

\author{
Authors \\ Hironori Yamamoto ${ }^{1}$ \\ Institutions \\ 1 Department of Medicine, Division of Gastroenterology, \\ Jichi Medical University, Shimotsuke, Japan \\ 2 Gastroenterology and Hepatology, Osaka Red Cross \\ Hospital, Osaka, Japan \\ 3 Shinozaki Medical Clinic, Utsunomiya, Japan \\ 4 Department of Surgery, Jichi Medical University, \\ Shimotsuke, Japan
}

Takeshi Yamashina', ${ }^{1}$, Yoshikazu Hayashi ${ }^{1}$, Hisashi Fukuda ${ }^{1}$, Masahiro Okada ${ }^{1}$, Takahito Takezawa ${ }^{1}$, Yasutoshi Kobayashi ${ }^{1}$, Hirotsugu Sakamoto ${ }^{1}$, Yoshimasa Miura ${ }^{1}$, Satoshi Shinozaki ${ }^{1}{ }^{3}$, Keijiro Sunada ${ }^{1}$, Alan Kawarai Lefor ${ }^{4}$,

submitted 29.6.2019

accepted after revision 2.5 .2020

Bibliography

DOI https://doi.org/10.1055/a-1190-7880 |

Endoscopy International Open 2020; 08: E1021-E1030

(c) Georg Thieme Verlag KG Stuttgart · New York

elSSN 2196-9736

Corresponding author

Hironori Yamamoto, MD, PhD, 3311-1 Yakushiji,

Shimotsuke, Tochigi 329-0498, Japan

Fax: +81-285-40-6598

ireef@jichi.ac.jp

\section{ABSTRACT}

Background and study aims Resecting large colorectal sessile tumors using endoscopic submucosal dissection (ESD) is challenging because of severe submucosal fibrosis. Previously, we reported that ESD strategy using the pocket- creation method (PCM) is useful for large colorectal sessile tumors, but there are no large studies reporting the effectiveness and safety of the PCM for resection of large colorectal sessile tumors.

Patients and methods This was a retrospective review of 90 large colorectal sessile tumors in 89 patients who underwent ESD in our institution. Large colorectal sessile tumors were defined as polypoid lesions $20 \mathrm{~mm}$ or more in diameter. We divided them into PCM $(n=40)$ and conventional method $(C M)$ groups $(n=50)$. The primary outcome measure was en bloc resection. The inverse-probability-treatment weighting (IPTW) approach was used to adjust for selection bias.

Results Both PCM and CM achieved high en bloc resection ( $100 \%$ vs. $94 \%$, non-adjusted $P=0.25$, IPTW-adjusted $P=$ $0.19)$ and $R 0$ resection rates ( $88 \%$ vs. $78 \%$, non-adjusted $P$ $=0.28$, IPTW-adjusted $P=0.27$ ). When PCM was used, the rate of pathologically negative vertical margins was significantly greater than with the CM (IPTW-adjusted $P=0.045$ ). The dissection time was significantly shorter (IPTW-adjusted $P=0.025$ ) and dissection speed faster (IPTW-adjusted $P=0.013$ ) using the PCM than when the CM was used. There was no significant difference in the incidence of adverse events (intraprocedural perforation and delayed bleeding, IPTW-adjusted $P=0.68$ ).

Conclusion Although en bloc resection and R0 resection rates were similar, PCM significantly increased the rate of negative vertical margins with rapid dissection for treatment of large colorectal sessile tumors.

\section{Introduction}

Colorectal cancer (CRC) is the third most commonly diagnosed cancer with nearly 1.6 million newly diagnosed patients annually and the fourth leading cause of cancer-related mortality with almost 771,000 deaths worldwide in 2013 [1-3]. However, mortality associated with CRC is much lower than incidence of
CRC, which means a favorable prognosis is expected if the cancer is detected at an early stage.

Endoscopic submucosal dissection (ESD) has the potential to become the common therapy for large superficial CRC. ESD results in a higher en bloc resection rate regardless of tumor size or location than endoscopic mucosal resection (EMR) [4] as long as the endoscope reaches the lesion. ESD allows accurate pathological diagnosis and is associated with a low recurrence 
rate [5-8]. However, there are reports that en bloc resection of large colorectal sessile (Is) tumors using ESD is challenging [912] because severe submucosal fibrosis and the muscle retracting (MR) sign are often present [9].

Recently, we reported that a new ESD strategy using the pocket-creation method (PCM) is useful for gastrointestinal ESD [13-19]. The important feature of PCM is the creation of a large submucosal pocket under the tumor, which facilitates maintenance of a thick submucosal layer, preventing leakage of the injected solution. PCM provides good traction with the tip of the hood stretching the submucosal tissue. The endoscopic view during PCM makes recognition of the muscularis easier, indicating a safe and appropriate dissection line. Therefore, a high-quality pathological specimen can be obtained. Vertical or over-a-fold tumor location can be changed to a tangential orientation which is ideal for ESD by insertion into the pocket. The tip of the endoscope in the submucosal pocket synchronizes with fluctuations due to breathing or heartbeat maintaining the endoscope stable. We previously reported that PCM is useful for resecting large colorectal sessile tumors with severe fibrosis [20]. Although we previously described the usefulness of PCM for colonic ESD [18], we excluded rectal lesions in that study as we were evaluating improvements in endoscope maneuverability by using PCM. However, the main problem with large colorectal sessile tumors is severe fibrosis and we conducted a new study to assess the effectiveness and safety of PCM for large sessile tumors in the colon and rectum. The aim of this study was to assess outcomes with PCM for resection of large colorectal sessile tumors compared with the conventional method (CM).

\section{Patients and methods}

\section{Patients}

The study was performed at Jichi Medical University Hospital. Consecutive patients with colorectal lesions in which ESD was attempted between April 2010 and January 2017 were enrolled in this analysis. Records of patients who underwent ESD of large colorectal sessile tumors were retrospectively reviewed. Patients with superficial elevated type lesions, pedunculated type lesions, non-neoplastic lesions, submucosal tumors or lesions $<20 \mathrm{~mm}$ were excluded.

According to the Paris endoscopic classification [21], superficial colorectal lesions are classified as polypoid or non-polypoid lesions. Lesions with a height exceeding about $2.5 \mathrm{~mm}$ were classified as polypoid lesions. Polypoid lesions are subclassified as type 0 -Ip (pedunculated) lesions, type 0-Isp (subpedunculated) lesions or type 0 -Is (sessile) lesions. Type 0 -Isp lesions are defined as intermediate and broad-based [22]. We defined large colorectal sessile tumors as polypoid lesions $\geq 20 \mathrm{~mm}$ in diameter, excluding pedunculated type lesions (type 0 -Is or Isp lesions $\geq 20 \mathrm{~mm}$ ).

A total of 887 colorectal lesions underwent ESD during the study period at Jichi Medical University Hospital. Of these 887 lesions, 753 superficial elevated type or pedunculated type lesions, 18 neuroendocrine tumors and 8 non-neoplastic lesions were excluded and 108 were sessile tumors. Of these 108 ses-

\section{Patients flow}

ESD performed for colorectal lesions between April 2010 and January $2017 n=887$

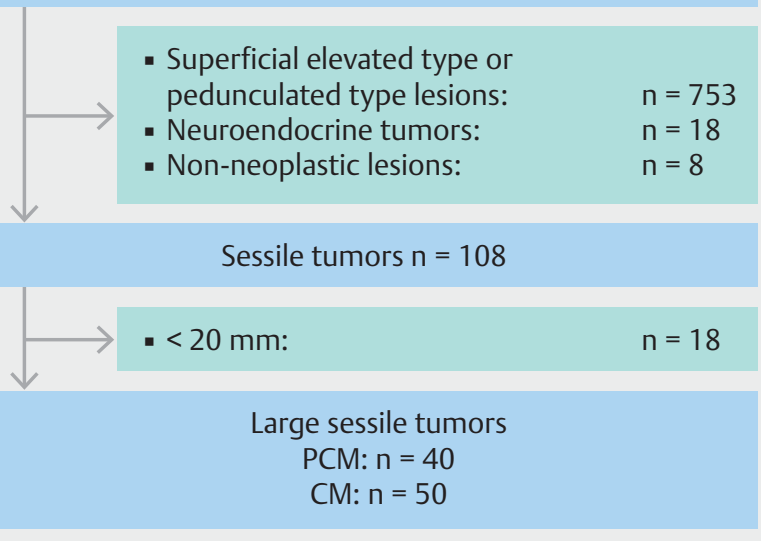

Fig. 1 Study flow diagram.

sile tumors, 18 were $<20 \mathrm{~mm}$ in diameter and were excluded. Thus, 90 large colorectal sessile tumors in 89 patients were included in the analysis ( $\triangleright$ Fig. 1 ).

This study was approved by the Institutional Ethics Review Board of Jichi Medical University Hospital (No.A16-114). This manuscript was written based on the Strengthening the Reporting of Observational Studies in Epidemiology (STROBE) Statement [23]. Data collected included age, gender (male or female), tumor location (cecum, ascending colon, transverse colon, descending colon, sigmoid colon or rectum), tumor size, morphological type (subpedunculated or sessile), histological type (adenoma, intramucosal carcinoma, the MR sign (positive or negative), slightly invasive submucosal carcinoma $(<1000 \mu \mathrm{m})$ or deeply invasive submucosal carcinoma $(\geq 1000 \mu \mathrm{m})$, en bloc resection rate, $\mathrm{R} 0$ resection rate, dissection time, dissection speed and adverse events (intraprocedural perforation or delayed bleeding).

\section{Indications for ESD}

Indications for colorectal ESD proposed by the Japan Society for Cancer of the Colon and Rectum (JSCCR) include: (1) neoplastic lesions $>20 \mathrm{~mm}$, determined unresectable by conventional EMR in an en bloc fashion; (2) colorectal tumors with a non-lifting sign after endoscopic submucosal injection; and (3) residual or recurrent colorectal tumors $>10 \mathrm{~mm}$, which were difficult to resect by conventional EMR. The first ESD with PCM was performed for a laterally spreading tumor, non-granular flat type with a biopsy scar in July 4, 2013. Before August 2013, we mainly performed ESD using the conventional method (CM group). After August 2013, we mainly performed ESD using the PCM (PCM group). 

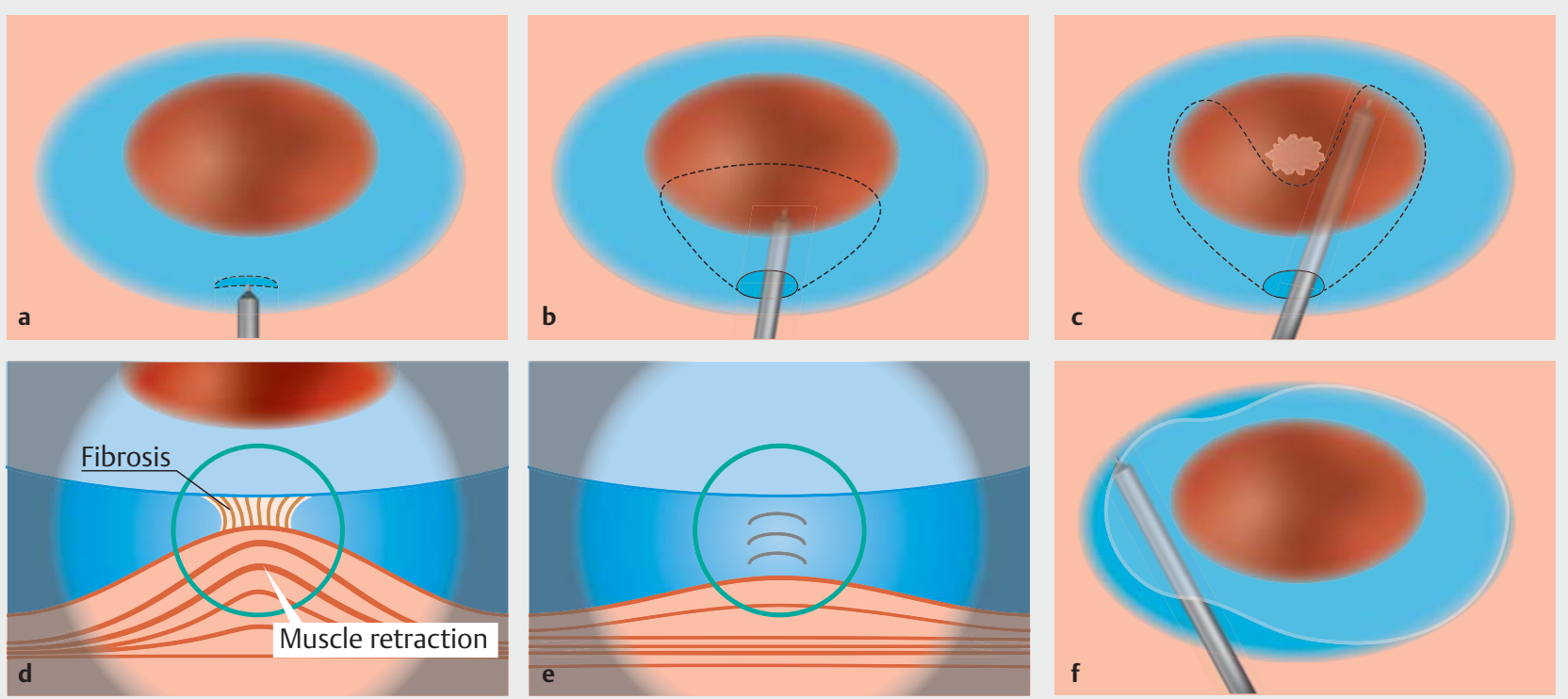

- Fig. 2 Large colorectal sessile tumors. a Initial mucosal incision approximately $20 \mathrm{~mm}$ long is made approximately $10 \mathrm{~mm}$ from the distal side of the tumor after submucosal injection. $\mathbf{b}$ Creation of a submucosal pocket under most of the tumor. $\mathbf{c}$, $\mathbf{d}$ Severe fibrosis with muscle retraction at the center of the lesion and extension of the submucosal pocket on both sides of the fibrosis. e Dissection of the fibrotic area. f Opening the lower side of the pocket proximally and dissection of the remaining area in the same manner.

\section{ESD procedure}

Bowel preparation was performed as described by Sakamoto et al. [13]. Glucagon or timepidium bromide hydrate was used to decrease colonic peristalsis, and pethidine and midazolam were used for sedation in most patients. The FlushKnife BT or BT-S (DK2618JB-15 or DK2620J-B15S; Fujifilm, Tokyo, Japan), or a DualKnife (KD-650Q; Olympus, Tokyo, Japan) were mainly used to perform colorectal ESD. Hot hemostatic forceps (HOYA Corporation, Tokyo, Japan) was used to control bleeding. A waterjet system (JW-2; Fujifilm, Tokyo, Japan), endoscopic $\mathrm{CO}_{2}$ regulation unit (GW-1; Fujifilm, Tokyo, Japan) and a small-caliber-tip transparent (ST or short ST) hood (DH-15GR or DH-28GR; Fujifilm, Tokyo, Japan) fitted to the tip of the endoscope were mainly used. A VIO 300D (ERBE Elektromedizin $\mathrm{GmbH}$, Tübingen, Germany) was used as a power source for cutting and coagulation of tissue, and all participating endoscopists used the same settings as described by Sakamoto et al [13]. All procedures were performed using a short-type therapeutic colonoscope (EC-580RD/M, Fujifilm, Tokyo, Japan) or short-type double-balloon endoscope (EC-450BI5 with TS13101, BI-530B with TS-13101 or El-580BT with TS-13101; Fujifilm). If patients had difficulties that precluded ESD using a conventional colonoscope, a double-balloon endoscope was used for ESD as we previously described [24]. For lesions in the rectum, an upper gastrointestinal endoscope (EG-450RD5, EGL580RD, Fujifilm, Tokyo, Japan) was sometimes used.

\section{Conventional and pocket-creation methods}

CM ESD was carried out as has previously been described [13, 18]. First, sodium hyaluronate solution (MucoUp; Seikagaku Corp, Tokyo, Japan) was injected into the submucosal layer un-

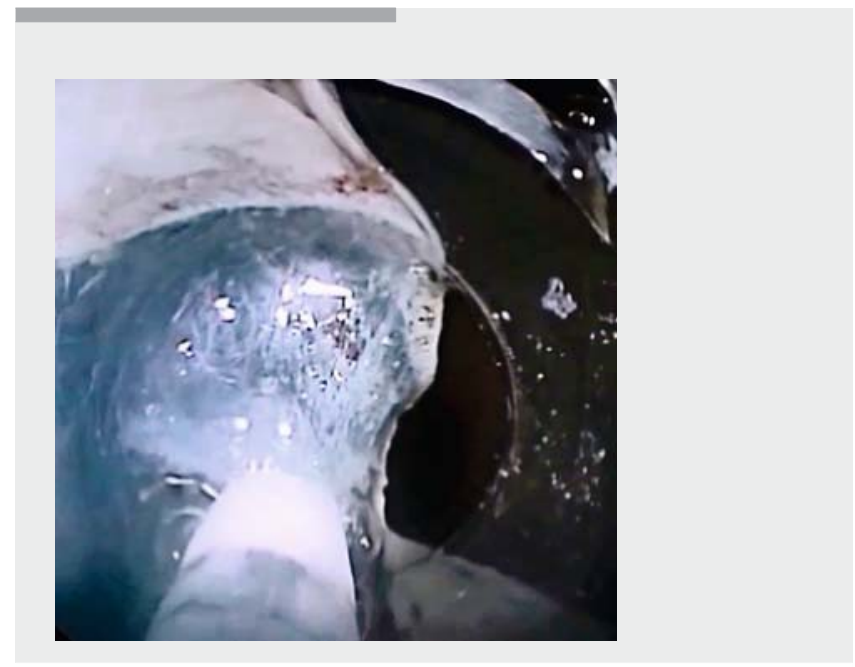

Video 1 Procedure of the pocket-creation method (PCM) of large colorectal sessile tumors.

der the lesion and around to create a long-lasting mucosal protrusion. An initial mucosal incision was made including at least one-quarter of the circumference, approximately $5 \mathrm{~mm}$ from the distal side of the tumor. Submucosal dissection was then performed from the distal to the proximal edge of the tumor to the two ends of the incision. After dissecting all initially incised mucosal areas, additional mucosal incisions and submucosal dissection were performed toward the proximal side in a repetitive manner.

ESD using the PCM was carried out as described by Hayashi et al [16] ( Fig.2) ( Video 1). Initially, submucosal injection 


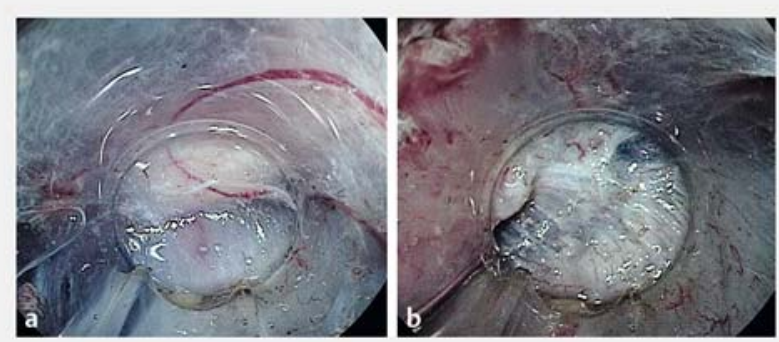

- Fig. 3 a Vertically elevated muscularis increasingly looks like severe fibrosis and it is difficult to identify the border. b Submucosal pockets are created on both sides of the fibrosis and the muscularis can be easily recognized.

was performed using the same method as with CM. An initial mucosal incision was made approximately $20 \mathrm{~mm}$ in length approximately $10 \mathrm{~mm}$ from the distal side of the tumor. Next, submucosal dissection was performed to make a pocket in the submucosal layer by inserting the tip of the endoscope with the ST or short ST hood under the mucosal tumor. The key point that differentiates this from the $\mathrm{CM}$ is completion of the submucosal dissection under the lesion before making the mucosal incision. If severe fibrosis recognizes at the center of the tumor, submucosal pockets are created on both sides of the fibrosis. By creating pockets on both sides of the fibrosis, the muscle layer can be clearly recognized and dissection of the fibrosis can then be easily achieved ( Fig.3) [20]. Generally, severe submucosal fibrosis is recognized to be oriented perpendicularly and the muscularis is oriented horizontally. In cases with a positive MR sign, there is a small amount of fibrotic submucosa between the top of the elevated muscularis below the tumor. Therefore, it is generally very difficult to identify the border. Hence, the conventionally used ST hood, providing traction and countertraction by its unique conical tip shape, can stretch the very thin fibrotic submucosa with fine perpendicular white-fiber lines identified in the muscularis consisting of horizontal muscle fibers. In addition, injection of $0.4 \%$ sodium hyaluronate containing indigo carmine at the fibrotic submucosa stretched by the ST hood can expand the submucosa and improve the contrast between the fibrotic submucosa with indigo carmine blue and the white muscle layer. The perpendicular crossing of these tissue fibers and the color contrast allow us to identify the border. After creation of a submucosal pocket under the tumor, the pocket is opened in a step-by-step manner, repeating the mucosal incision and subsequent submucosal dissection, up to the proximal side of the tumor. Finally, the upper area is opened in the same manner to complete the en bloc resection. The major difference from the $\mathrm{CM}$ is the completion of submucosal dissection under the tumor with a minimal mucosal incision when using the PCM.

\section{Data analysis and definition of outcomes}

The primary outcome was the en bloc resection rate of the large colorectal sessile tumors performed using the CM and PCM. Secondary outcomes included $\mathrm{R} 0$ resection rate, adverse events (AEs), dissection time (min), and dissection speed $\left(\mathrm{mm}^{2} / \mathrm{min}\right)$. The area of the resected specimen $\left(\mathrm{mm}^{2}\right)$ was calculated using the following formula: area=major axis $(\mathrm{mm}) /$ $2 \times$ minor axis $(\mathrm{mm}) / 2 \times 3.14$ [15]. The dissection speed $\left(\mathrm{mm}^{2}\right.$ / $\mathrm{min}$ ) was calculated by using the area of the resected specimen $\left(\mathrm{mm}^{2}\right)$ / dissection time (min) [15]. Dissection time (min) was defined from the start of cutting the mucosa to completion of resection. En bloc resection was defined as a tumor removed as a single specimen. $\mathrm{R} 0$ resection was defined as an en bloc resection with pathologically negative resection margins (vertical and lateral). As described by Toyonaga et al., we defined the MR sign as the appearance of the muscle layer in severe fibrosis under a colorectal tumor being drawn by the tumor to form a triangular shape [9]. Intraprocedural perforation was defined as visible luminal contents outside the gastrointestinal tract through a hole, or free air on abdominal computed tomography scan after ESD [25]. Delayed bleeding was defined as overt bleeding requiring endoscopic hemostasis within 14 days after ESD. All AEs were assessed according to the National Cancer Institute Common Terminology Criteria for Adverse Events version 4.0 [26].

\section{Statistical analysis}

Results for parametric data are reported as the mean (standard deviation, SD), and nonparametric data are reported as the median (range). The $x^{2}$ test or Fisher's exact test was used for analysis of categorical data. Quantitative data were compared using the Mann-Whitney $U$ test. In addition, the inverse probability of treatment weighting (IPTW) method based on the propensity score was used to reduce the effect of selection bias between the PCM and CM groups. Variables entered in the IPTW model were experience of the endoscopist, tumor size, tumor location, and tumor morphology which were determined on the basis of previous reports $[27,28]$ and then, applied to a generalized linear model procedure to compare the primary and secondary outcomes between the two groups. All statistical work was carried out using SPSS statistics version 24 (SPSS, Chicago, Illinois, United States).

\section{Results}

The 90 lesions in 89 patients are divided into the PCM $(n=40)$ and CM groups $(n=50)$, and characteristics of patients and lesions are presented in $>$ Table $\mathbf{1}$. There were no statistically significant differences in gender $(P=0.61)$, age $(P=0.27)$, tumor location $(P=0.69)$, size $(P=0.77)$ or morphology $(P=0.47)$ in these two groups.

\section{Procedure-related outcomes}

ESD procedures for large colorectal sessile tumors were carried out by 17 endoscopists. Details of the endoscopists' experience are shown in $>$ Table 2. Both PCM and CM achieved high en bloc resection rates by 17 endoscopists (100\% [40/40] vs. 94\% [47/ 50], $P=0.25$ ) ( Table 3 ). In six cases in the CM group, ESD could not be completed. In one case there was an intraprocedural perforation. Although the perforation was endoscopically closed with clips, it was difficult to continue the ESD procedure. 
- Table 1 Characteristics of patients and lesions.

\begin{tabular}{|c|c|c|c|}
\hline & Pocket-creation method & Conventional method & $P$ value \\
\hline Patients/lesions & $40 / 40$ & $49 / 50$ & \multirow[t]{3}{*}{$0.61^{1}$} \\
\hline - Male & $25(63 \%)$ & $28(57 \%)$ & \\
\hline - Female & $15(38 \%)$ & $21(43 \%)$ & \\
\hline Median age & 64.5 & 67 & \multirow[t]{2}{*}{$0.27^{2}$} \\
\hline " (range, years) & $(42-90)$ & $(42-88)$ & \\
\hline \multicolumn{3}{|l|}{ Location } & \multirow[t]{4}{*}{$0.69^{1}$} \\
\hline - Proximal colon & $15(38 \%)$ & $18(36 \%)$ & \\
\hline - Distal colon & $6(15 \%)$ & $11(22 \%)$ & \\
\hline - Rectum & $19(48 \%)$ & $21(42 \%)$ & \\
\hline \multicolumn{3}{|l|}{ Morphology } & \multirow[t]{3}{*}{$0.47^{1}$} \\
\hline - Semipedunculated type & $10(25 \%)$ & $16(32 \%)$ & \\
\hline - Sessile type & $30(75 \%)$ & $34(68 \%)$ & \\
\hline Median tumor size & 30.5 & 30.5 & \multirow[t]{2}{*}{$0.77^{2}$} \\
\hline - (range, mm) & $(20-57)$ & $(20-90)$ & \\
\hline \multicolumn{3}{|l|}{ Endoscope } & \multirow[t]{3}{*}{$>0.99^{3}$} \\
\hline - Short-type colonoscope ${ }^{4}$ & $37(93 \%)$ & $46(93 \%)$ & \\
\hline - Double-balloon endoscope & $3(8 \%)$ & $4(7 \%)$ & \\
\hline \multicolumn{3}{|l|}{ Muscle retracting sign } & \multirow[t]{3}{*}{$0.76^{3}$} \\
\hline - Positive & $6(15 \%)$ & $6(12 \%)$ & \\
\hline - Negative & $34(85 \%)$ & $44(88 \%)$ & \\
\hline \multicolumn{3}{|l|}{ Histological type } & \multirow[t]{5}{*}{$0.10^{3}$} \\
\hline - Adenoma & $11(28 \%)$ & $15(30 \%)$ & \\
\hline - Intramucosal Carcinoma & $24(60 \%)$ & $20(40 \%)$ & \\
\hline - Slightly invasive submucosal carcinoma $<1000 \mu \mathrm{m}$ & $1(3 \%)$ & $8(16 \%)$ & \\
\hline - Deeply invasive submucosal carcinoma $\geq 1000 \mu \mathrm{m}$ & $4(10 \%)$ & $7(14 \%)$ & \\
\hline \multicolumn{4}{|l|}{$\begin{array}{l}11 \text { X2 test } \\
{ }^{2} \text { Mann-Whitney U test } \\
{ }^{3} \text { Fisher's exact test } \\
{ }^{4} \text { EC- } 580 \text { RD/M (Fujifilm, Tokyo, Japan) } \\
{ }^{5} \text { EC-450BI5 with TS-13101 or BI-530B with TS-13101 (Fujifilm) }\end{array}$} \\
\hline
\end{tabular}

Another was recognized as a deeply invasive submucosal carcinoma for which it was difficult to distinguish the submucosal layer from the muscularis propria due to the invasiveness of the lesion. These two patients underwent colectomies to treat residual lesions at later dates. Surgical histopathological examinations of these two discontinued-ESD cases showed deeply invasive submucosal carcinoma and intramucosal carcinoma, respectively. In four of the six cases using CM in which ESD could not be completed, lesions were finally resected using a snare because of severe submucosal fibrosis with MR. Three of four cases achieved an en bloc resection with a snare and the other was entirely removed in a piecemeal fashion with a snare. No residual tumor was found endoscopically in these four cases. Histopathological examination of these four cases re- sected with a snare showed an adenoma, an intramucosal carcinoma, and two deeply invasive submucosal carcinomas. There were no cases requiring snare or piecemeal resection in the PCM group. There were no cases that changed from PCM to CM or CM to PCM. All PCM cases for large colorectal sessile tumors were completed using ESD.

There were 11 deeply invasive submucosal lesions, four in the PCM and seven in the CM groups. In these cases, 10 patients underwent additional surgery at a later date and one patient in the CM group was not a candidate for surgery because of comorbidities. One lesion with lymphovascular invasion with a slightly invasive submucosal carcinoma in the CM group was followed up without additional treatment for personal reasons ( Table 3). 
- Table 2 ESD procedural experience of each endoscopist in this study period.

\begin{tabular}{|c|c|c|c|}
\hline $\begin{array}{l}\text { Endos- } \\
\text { copist }\end{array}$ & $\begin{array}{l}\text { Colorectal } \\
\text { ESD cases } \\
\text { performed } \\
\text { before this } \\
\text { study }\end{array}$ & $\begin{array}{l}\text { Pocket-creation } \\
\text { method for } \\
\text { large sessile } \\
\text { tumors/total } \\
\text { pocket-creation } \\
\text { method }\end{array}$ & $\begin{array}{l}\text { Conventional } \\
\text { method for } \\
\text { large sessile } \\
\text { tumors/total } \\
\text { conventional } \\
\text { method }\end{array}$ \\
\hline$A^{1}$ & 36 & $7 / 83$ & $5 / 37$ \\
\hline $\mathrm{B}^{1}$ & 172 & $7 / 35$ & $4 / 39$ \\
\hline $\mathrm{C}^{1}$ & 134 & $5 / 62$ & $12 / 56$ \\
\hline D & 4 & $5 / 30$ & $0 / 0$ \\
\hline$E^{1}$ & 203 & $4 / 15$ & $9 / 68$ \\
\hline $\mathrm{F}$ & 0 & $2 / 22$ & $2 / 42$ \\
\hline G & 0 & $2 / 24$ & $0 / 0$ \\
\hline $\mathrm{H}$ & 0 & $2 / 37$ & $0 / 0$ \\
\hline 1 & 0 & $1 / 19$ & $6 / 41$ \\
\hline J & 0 & $1 / 17$ & $5 / 26$ \\
\hline K & 2 & $1 / 57$ & $1 / 8$ \\
\hline L & 0 & $1 / 7$ & $0 / 3$ \\
\hline M & 0 & $1 / 1$ & $0 / 0$ \\
\hline $\mathrm{N}$ & 0 & $1 / 6$ & $0 / 1$ \\
\hline O & 0 & $0 / 0$ & $3 / 8$ \\
\hline $\mathrm{P}$ & 0 & $0 / 0$ & $2 / 15$ \\
\hline Q & 0 & $0 / 0$ & $1 / 3$ \\
\hline Others & 0 & $0 / 75$ & $0 / 50$ \\
\hline \multicolumn{4}{|c|}{$\begin{array}{l}\text { ESD, endoscopic submucosal dissection } \\
{ }^{1} \text { Expert endoscopist. }\end{array}$} \\
\hline
\end{tabular}

There were no differences in $\mathrm{R} 0$ resection rates (88\%, vs. $78 \%, P=0.28)$. The dissection time was significantly shorter $(P=0.036)$ and dissection speed significantly faster $(P=0.020)$ using PCM than when CM was used. When PCM was used, the rate of pathologically negative vertical margins was significantly greater than when $\mathrm{CM}$ was used $(P=0.038)$. The rate of pathologically negative margins was $100 \%$ in PCM with deeply invasive submucosal carcinomas, $1000 \mu \mathrm{m}$ or more lesions and tend to be better compared to the CM, (100\%, 4/4 vs. $29 \%, 2 / 7$, $P=0.06)$ ( $\triangleright$ Table 3$)$. After adjustment with IPTW, dissection time was also significantly shorter (odds ratio $[O R]=2.25, P=$ $0.025)$ and dissection speed significantly faster $(O R=2.53, P=$ 0.013 ) using PCM with a significantly greater rate of pathologically negative vertical margins $(O R=8.66, P=0.045)$.

The MR sign was positive in $13 \%$ (12/60) of all lesions. In MRpositive lesions, PCM achieved a $100 \%$ en bloc resection rate and an $83 \%$ (5/6) rate of pathologically negative vertical margins rates. Although using CM achieved an $83 \%$ en bloc resection rate, the rate of pathologically negative vertical margins was $33 \%$ (2/6) for these lesions. In addition, PCM achieved pa- thologically negative vertical margin in MR- positive lesions even with deeply invasive submucosal carcinoma (2/2) compared with CM (1/4) ( Table4). In deeply invasive submucosal lesions and/or lesions which were MR sign-positive, PCM achieved higher pathologically negative vertical margin rate with shorter median dissection time compared with CM ( $\triangleright$ Table 5).

\section{Adverse events}

Intraprocedural perforation occurred in four patients in the CM group and one in the PCM group. All perforations were small and managed non-operatively by endoscopic clipping. Delayed bleeding after using CM occurred in one patient and was managed by endoscopic hemostasis using hemostatic forceps. No serious AEs requiring surgery, or deaths, occurred during the study period. The difference in incidence of AEs (intraprocedural perforation and delayed bleeding $2.5 \%, 1 / 40$ vs. $10 \%, 5 / 50$, non-adjusted $P=0.22$, IPTW-adjusted $P=0.68$ ) was not statistically significant between the two groups.

\section{Discussion}

PCM achieved an en bloc resection rate of $100 \%$ and an R0 resection rate of $88 \%$ for difficult large colorectal sessile tumors with a significantly shorter dissection time compared with CM. Occasionally, en bloc resection of large colorectal sessile tumors with ESD is challenging because of submucosal fibrosis and muscle retraction. In this study, although the PCM achieved en bloc resection in all cases, there was no statistical difference in the en bloc resection rate between the two groups. However, ESD procedures for two cases in the CM group were discontinued and colectomies performed to treat the residual lesions at a later date. ESD for four cases in the CM group could not be completed and the entire lesions finally removed with a snare. One case treated by colectomy was an intramucosal carcinoma and one case treated by snare resection was a piecemeal resection. There was no case necessitating a snare resection or converted to colectomy in the PCM group. The intramucosal carcinoma treated by colectomy and the piecemeal resection by snare might have avoided the need for other modalities if the PCM had been used. Some studies reported that presence of fibrosis is related to perforation and incomplete resection $[28,29]$. Toyonaga et al. described that there are two possible reasons for muscle retraction. One is due to invasion of the submucosa or deeper by tumor, and the other is fibrosis caused by the mechanical force generated between the submucosa and the muscularis due to intestinal peristalsis [9]. Despite MR without lifting the submucosa, one-third of the procedures are curative because the MR is due to a benign cause or tumor invasion is limited to the mucosa or superficial submucosa $(<1000 \mu \mathrm{m}$ from the muscularis mucosa) [9]. As a result of our study of MR sign-positive lesions, PCM achieved an $83 \%$ (5/6) rate of pathologically negative vertical margins with only one small intraprocedural perforation. We think it is worthwhile to perform PCM for large colorectal sessile tumors potentially associated with MR and severe fibrosis. 
- Table 3 Procedure-related outcomes.

\begin{tabular}{|c|c|c|c|c|}
\hline & $\begin{array}{l}\text { Pocket-creation } \\
\text { method }\end{array}$ & $\begin{array}{l}\text { Conventional } \\
\text { method }\end{array}$ & $\begin{array}{l}\text { Non-adjusted } \\
P \text { value }\end{array}$ & $\begin{array}{l}\text { IPTW-adjusted } \\
P \text { value OR }(95 \% \mathrm{CI})\end{array}$ \\
\hline En bloc resection & $\begin{array}{l}40 / 40 \\
(100 \%)\end{array}$ & $\begin{array}{l}47 / 50 \\
(94 \%)\end{array}$ & $0.25^{1}$ & $\begin{array}{l}0.19^{1} \\
6.6(0.31-141.39)\end{array}$ \\
\hline R0 resection & $\begin{array}{l}35 / 40 \\
(88 \%)\end{array}$ & $\begin{array}{l}39 / 50 \\
(78 \%)\end{array}$ & $0.28^{1}$ & $\begin{array}{l}0.27^{2} \\
1.92(0.6-6.15)\end{array}$ \\
\hline $\begin{array}{l}\text { Median dissection time } \\
\text { (range, minutes) }\end{array}$ & $\begin{array}{l}53.5 \\
(16-123)\end{array}$ & $\begin{array}{l}63 \\
(7-300)\end{array}$ & $0.036^{3}$ & $\begin{array}{l}0.025^{2} \\
2.25(1.11-4.58)\end{array}$ \\
\hline $\begin{array}{l}\text { Median dissection speed } \\
{\text { (ranges, } \mathrm{mm}^{2} / \text { minutes) }}^{4}\end{array}$ & $\begin{array}{l}19.3 \\
(5.8-53)\end{array}$ & $\begin{array}{l}15.9 \\
(3.1-50.4)\end{array}$ & $0.020^{3}$ & $\begin{array}{l}0.013^{2} \\
2.53(1.22-5.25)\end{array}$ \\
\hline \multicolumn{3}{|l|}{ Horizontal margin } & \multirow[t]{3}{*}{$0.99^{2}$} & \multirow{3}{*}{$\begin{array}{l}1.0^{2} \\
1.0(0.24-4.06)\end{array}$} \\
\hline - Negative & $\begin{array}{l}36 \\
(90 \%)\end{array}$ & $\begin{array}{l}45 \\
(90 \%)\end{array}$ & & \\
\hline - Positive/unclear & $\begin{array}{l}1 / 3 \\
(10 \%)\end{array}$ & $\begin{array}{l}1 / 4 \\
(10 \%)\end{array}$ & & \\
\hline \multicolumn{3}{|l|}{ Vertical margin } & \multirow[t]{3}{*}{$0.038^{1}$} & \multirow{3}{*}{$\begin{array}{l}0.045^{2} \\
8.66(1.05-71.61)\end{array}$} \\
\hline - Negative & $\begin{array}{l}39 \\
(98 \%)\end{array}$ & $\begin{array}{l}41 \\
(82 \%)\end{array}$ & & \\
\hline - Positive/unclear & $\begin{array}{l}1 / 0 \\
(2 \%)\end{array}$ & $\begin{array}{l}7 / 2 \\
(18 \%)\end{array}$ & & \\
\hline pVM0 resection/ shallow lesion ${ }^{4}$ & $\begin{array}{l}35 / 36 \\
(97 \%)\end{array}$ & $\begin{array}{l}39 / 43 \\
(91 \%)\end{array}$ & \multirow[t]{2}{*}{$0.37^{1}$} & \\
\hline $\begin{array}{l}\text { (adenoma, intramucosal carcinoma and slightly } \\
\text { invasive submucosal carcinoma }<1000 \mu \mathrm{m} \text { ) }\end{array}$ & $(11,24,1)$ & $(15,20,8)$ & & \\
\hline $\begin{array}{l}\text { pVM0 resection/ deeply invasive submucosal } \\
\text { carcinoma } \geq 1000 \mu \mathrm{m}\end{array}$ & $\begin{array}{l}4 / 4 \\
(100 \%)\end{array}$ & $\begin{array}{l}2 / 7 \\
(29 \%)\end{array}$ & $0.06^{1}$ & \\
\hline \multicolumn{3}{|l|}{ Endoscopist } & \multirow[t]{3}{*}{1,0} & \\
\hline - Expert ${ }^{5}$ & $23(58 \%)$ & $30(60 \%)$ & & \\
\hline - Non expert ${ }^{6}$ & $17(43 \%)$ & $20(40 \%)$ & & \\
\hline \multicolumn{3}{|l|}{ Adverse events } & \multirow[t]{3}{*}{$0.22^{1}$} & \multirow{3}{*}{$\begin{array}{l}0.68^{2} \\
0.69(0.12-4.03)\end{array}$} \\
\hline - Intraprocedural perforation & $1(3 \%)$ & $4(8 \%)$ & & \\
\hline - Delayed bleeding & $0(0 \%)$ & $1(3 \%)$ & & \\
\hline \multicolumn{5}{|l|}{$\begin{array}{l}\text { OR, odds ratio; } \mathrm{Cl} \text {, confidence interval; } \mathrm{VM} \text {, vert } \\
{ }^{1} \text { Fisher's exact test } \\
{ }^{2} \text { Generalized estimating equations } \\
{ }^{3} \text { Mann-Whitney U test } \\
{ }^{4} \text { Measured adequate specimen case } \\
{ }^{5} \text { ESD experience before study } 5 \text { or more cases } \\
{ }^{6} \text { ESD experience before study less than } 5 \text { cases }\end{array}$} \\
\hline
\end{tabular}

PCM has several advantages including maintenance of a thick submucosal layer with a minimal mucosal incision, which prevents leakage of injected solution and provides good traction. This also facilitates tissue traction, resulting in speedy submucosal dissection, stable visualization of the muscularis even in severe fibrosis or with MR sign, which is one of the factors associated with ESD technical difficulties because of the thin and obscuring submucosa. When the endoscope burrows into the created pocket, it alleviates problems associated with respiratory, heartbeat or peristalsis movement by synchroniz- ing the endoscope in the pocket while maintaining good endoscopic maneuverability [13-20]. The PCM technique allows safe en bloc ESD and complete resection of large colorectal sessile tumors even in the presence of severe submucosal fibrosis and the MR sign. Actually, in this study, dissection time and speed were significantly shorter and faster using PCM than when CM was used. Although we examined only a few cases, median dissection time of PCM for deeply invasive submucosal carcinoma lesions and/or that was MR sign-positive was shorter than that of CM. 
- Table 4 pVM0 stratified by muscle retracting sign.

\begin{tabular}{l|l|c|}
\hline Pocket-creation method & Muscle retracting sign positive & Muscle-retracting sign negative \\
\hline pVM0 resection/shallow lesion ${ }^{1}$ & $3 / 4$ & $32 / 32$ \\
\hline pVM0 resection/deeply invasive submucosal carcinoma $\geq 1000 \mu \mathrm{m}$ & $2 / 2$ & $2 / 2$ \\
\hline Conventional method & & $38 / 41$ \\
\hline pVM0 resection/shallow lesion ${ }^{1}$ & $1 / 2$ & $1 / 3$ \\
\hline \begin{tabular}{l} 
pVM0 resection/ deeply invasive submucosal carcinoma $\geq 1000 \mu \mathrm{m}$ \\
\hline $\begin{array}{l}\text { VM, vertical margin. } \\
\text { 1 adenoma, intramucosal carcinoma and slightly invasive submucosal carcinoma }<1000 \mu \mathrm{m}\end{array}$
\end{tabular} \\
\hline
\end{tabular}

- Table 5 pVM0 stratified by muscle-retracting sign and/or presence of deeply invasive submucosal carcinoma

\begin{tabular}{|l|c|c|c|}
\hline & Pocket-creation method & Conventional method & $P$ value \\
\hline $\begin{array}{l}\text { PVM0 resection/deeply invasive submucosal carcinoma } \geq 1000 \mu \mathrm{m} \text { and/or } \\
\text { muscle retracting sign }\end{array}$ & $7 / 8$ & $3 / 9$ \\
\hline $\begin{array}{l}\text { Dissection time in deeply invasive submucosal carcinoma } \geq 1000 \mu \mathrm{m} \text { and/or } \\
\text { muscle retracting sign }\end{array}$ & 62.5 & 167 \\
\hline $\begin{array}{l}\text { VM, vertical margin. } \\
\text { 2 Fisher's exact test }\end{array}$ & & 0.0491 \\
\hline
\end{tabular}

Although the rate of negative horizontal margins was similar in both groups, when PCM was used, the rate of pathologically negative vertical margins was significantly greater than when using CM. Furthermore, PCM also achieved a $100 \%$ pathologically negative vertical margin rate in resection of deeply invasive submucosal carcinoma lesions with or without the MR sign. Compared with CM, PCM also may be able to overcome difficulties such as a thin submucosa. Although there were no statistically significant differences in histological type among two groups, two cases forced to convert surgery because of severe fibrosis in the CM group. These results suggest that PCM is a preferable method for large colorectal sessile tumors in which difficulty with CM is anticipated. If the resected submucosal layer is insufficient, it is difficult to make an exact pathological diagnosis identifying lymphatic, vascular or submucosal invasion. PCM facilitates recognition of the muscularis and a tangential approach to the muscle layer by adjusting the angle of approach to the muscularis, resulting in safe and appropriate dissection line just above the muscularis. This minimizes tissue damage due to thermocoagulation in the resected specimen, resulting in a high-quality pathology specimen. These factors facilitate resection of a thick submucosal layer with less tissue trauma, ensuring accurate pathological assessment [13-20].

Shi et al. reported that a retroflex view is an effective and safe alternative to achieve en bloc $\mathrm{R} 0$ resection of giant subpedunculated colorectal tumors that are difficult to resect by polypectomy [11]. However, they described that in the sigmoid colon and some other locations in the colon, they were unable to achieve retroflexion due to a loop or narrow colonic lumen. PCM does not require the retroflex procedure and in this study, we achieved a $100 \%(40 / 40)$ en bloc resection rate. There were no differences in en bloc resection rates, R0 resection rates, dissection time or AEs for rectal lesions in the two groups. The major problem with large colorectal sessile tumors is severe fibrosis and, at this point, we think PCM is effective for large colorectal sessile tumors regardless of tumor location. This further suggests that PCM would be optimal for ESD of large colorectal sessile tumors without requiring retroflexion.

Nomura et al. and Abiko et al. reported on the usefulness of the clip to improve stability when opening the pocket $[30,31]$. When the pocket is opened, especially on the gravity side, methods of applying traction, such as the S-O clip, may be useful to easily incise the mucosa. However, in creating the submucosal pocket, once the tip of the endoscope is inserted into the submucosal layer, the fixed tip of the endoscope with a transparent hood easily provides traction and counter-traction to stretch the submucosa. Hence, because most traction devices can provide traction but not countertraction, we must apply countertraction using gravity, endoscope-tip pressure and/or insufflation. Without appropriate countertraction, traction devices may lift the muscularis without adequate stretching of the submucosa, which can lead to accidental damage to the muscularis with the electro-knife.

This study had several limitations. First, it was retrospective. Since 2013, we have mostly been performing ESD using PCM. There is a possibility that performance improved with increased experience over time. Second, it was a single-center study. The endoscopists participating in this study have extensive experience and the results may not be generalizable. Third, the sample size of this study of large sessile tumors resections was small because ESD of large colorectal sessile tumors was performed less often; about $10 \%$ in patients with colorectal lesions 
in which ESD was attempted in our institution. Despite the small sample size, we compared PCM and CM using the IPTW method based on propensity score to minimize the effects of selection bias: operators' experience, location, size, and morphology. We believe the quality of the data warrant serious consideration of these findings. Because the frequency of large colorectal sessile tumors is low, further multicenter studies are needed to evaluate resection and $\mathrm{R} 0$ resection.

\section{Conclusion}

Although resection and R0 resection rates were similar, PCM significantly increases the rate of negative vertical margins with rapid dissection for treatment of large colorectal sessile tumors with no increased incidence of significant AEs. A multicenter trial is warranted to confirm the validity of the current study.

\section{Acknowledgements}

The authors thank all endoscopists and their colleagues at Jichi Medical University who supported the study.

\section{Competing interests}

Dr. Yamamoto has patents for the double-balloon endoscope produced by Fujifilm Corp. He also serves as a consultant for and has received honoraria, grants, and royalties from Fujifilm Corp.

\section{References}

[1] Colorectal cancer statistics. World Cancer Research Fund International; Available from: http://www.wcrf.org/int/cancer-facts-figures/ data-specific-cancers/colorectal-cancer-statistics

[2] WHO. The global burden of disease: 2004 update. World Health Organization; Available from: http://www.who.int/healthinfo/global_burden_disease/2004_report_update/en/

[3] Fitzmaurice C, Dicker D, Pain A et al. The Global Burden of Cancer 2013. JAMA Oncol. Europe PMC Funders 2015; 1: 505-527

[4] Saito Y, Fukuzawa M, Matsuda T et al. Clinical outcome of endoscopic submucosal dissection versus endoscopic mucosal resection of large colorectal tumors as determined by curative resection. Surg Endosc 2010; 24: 343-352

[5] Ono $\mathrm{H}$, Kondo $\mathrm{H}$, Gotoda T et al. Endoscopic mucosal resection for treatment of early gastric cancer. Gut 2001; 48: 225-229

[6] Fujishiro M, Yahagi N, Kakushima N et al. Outcomes of endoscopic submucosal dissection for colorectal epithelial neoplasms in 200 consecutive cases. Clin Gastroenterol Hepatol 2007; 5: 678-683

[7] Takeuchi $\mathrm{Y}$, Uedo N, lishi $\mathrm{H}$ et al. Endoscopic submucosal dissection with insulated-tip knife for large mucosal early gastric cancer: a feasibility study (with videos). Gastrointest Endosc 2007; 66: 186-193

[8] Yamamoto H, Yahagi N, Oyama T. Mucosectomy in the colon with endoscopic submucosal dissection. Endoscopy 2005; 37: 764-768

[9] Toyonaga T, Tanaka S, Man-I M et al. Clinical significance of the muscle-retracting sign during colorectal endoscopic submucosal dissection. Endosc Int Open 2015; 3: E246-E251
[10] Choi YS, Lee JB, Lee E-J et al. Can endoscopic submucosal dissection technique be an alternative treatment option for a difficult giant ( $\geq 30 \mathrm{~mm}$ ) pedunculated colorectal polyp? Dis Colon Rectum 2013: 56: 660-666

[11] Shi H, Su-Yu C, Zhao-Fei X et al. Modified endoscopic submucosal dissection technique to achieve en bloc resection of giant $(\geq 3 \mathrm{~cm})$ subpedunculated (stalk $<1 \mathrm{~cm}$ ) colorectal tumors. Gastroenterol Hepatol Open Access 2016; 4: 00114

[12] Rahni DO, Toyonaga T, Ohara Y et al. First reported case of per anal endoscopic myectomy (PAEM): A novel endoscopic technique for resection of lesions with severe fibrosis in the rectum. Endosc Int Open 2017; 5: E146-E150

[13] Sakamoto H, Hayashi Y, Miura Y et al. Pocket-creation method facilitates endoscopic submucosal dissection of colorectal laterally spreading tumors, non-granular type. Endosc Int Open 2017; 5: E123-E129

[14] Miura Y, Shinozaki S, Hayashi Y et al. Duodenal endoscopic submucosal dissection is feasible using the pocket-creation method. Endoscopy 2016; 49: 8-14

[15] Hayashi Y, Shinozaki S, Sunada K et al. Efficacy and safety of endoscopic submucosal dissection for superficial colorectal tumors more than $50 \mathrm{~mm}$ in diameter. Gastrointest Endosc 2016; 83: 602-607

[16] Hayashi Y, Miura Y, Yamamoto H. Pocket-creation method for the safe, reliable, and efficient endoscopic submucosal dissection of colorectal lateral spreading tumors. Dig Endosc 2015; 27: 534-535

[17] Miura Y, Hayashi Y, Lefor A et al. The pocket-creation method of ESD for gastric neoplasms. Gastrointest Endosc 2016; 83: 457-458

[18] Takezawa T, Hayashi Y, Shinozaki S et al. The Pocket-creation method facilitates colonic endoscopic submucosal dissection (with video). Gastrointest Endosc 2019; 89: 1045-1053

[19] Yamashina T, Nemoto D, Hayashi Y et al. A prospective randomized trial comparing the pocket-creation method and conventional method of colorectal endoscopic submucosal dissection. Gastrointest Endosc 2020: doi:10.1016/j.gie.2020.02.034 [Epub ahead of print]

[20] Hayashi Y, Sunada K, Takahashi H et al. Pocket-creation method of endoscopic submucosal dissection to achieve en bloc resection of giant colorectal subpedunculated neoplastic lesions. Endoscopy 2014; 46: E421-E422

[21] The Paris endoscopic classification of superficial neoplastic lesions: esophagus, stomach, and colon. Gastrointest Endosc 2003; 58: S3S43

[22] Soetikno R, Friedland S, Kaltenbach T et al. Nonpolypoid (flat and depressed) colorectal neoplasms. Gastroenterology 2006; 130: 566576

[23] von Elm E, Altman DG, Egger M et al. The Strengthening the Reporting of Observational Studies in Epidemiology (STROBE) statement: guidelines for reporting observational studies. Ann Intern Med 2007; 147: 573-577

[24] Yamashina T, Hayashi Y, Sakamoto H et al. Balloon-assisted endoscopy facilitates endoscopic submucosal dissection of difficult superficial proximal colon tumors. Endoscopy 2018; 50: 800-808

[25] Cotton PB, Eisen GM, Aabakken L et al. A lexicon for endoscopic adverse events: report of an ASGE workshop. Gastrointest Endosc 2010; 71: 446-454

[26] National Cancer Institute Common Terminology Criteria for Adverse Events (CTCAE) v. 4.0. Available from: http://evs.nci.nih.gov/ftp1/ CTCAE/About.html

[27] Imai K, Hotta K, Yamaguchi Y et al. Preoperative indicators of failure of en bloc resection or perforation in colorectal endoscopic submucosal dissection: implications for lesion stratification by technical difficulties during stepwise training. Gastrointest Endosc 2016; 83: $954-$ 962 
[28] Takeuchi Y, lishi H, Tanaka S et al. Factors associated with technical difficulties and adverse events of colorectal endoscopic submucosal dissection: retrospective exploratory factor analysis of a multicenter prospective cohort. Int J Colorectal Dis 2014; 29: 1275-1284

[29] Hayashi N, Tanaka S, Nishiyama S et al. Predictors of incomplete resection and perforation associated with endoscopic submucosal dissection for colorectal tumors. Gastrointest Endosc 2014; 79: 427-435
[30] Nomura T, Hayashi Y, Lee RF et al. Pocket-creation method using a new technique of single-clip traction for colorectal endoscopic submucosal dissection. Endoscopy 2020; 52: E208-E210

[31] Abiko S, Yoshikawa A, Harada K et al. Usefulness of a clutch cutter combined with an $\mathrm{S}$-O clip in improving stability when opening the pocket in the pocket-creation method. Endoscopy 2020; 42: E128E129 